\title{
SRTM DEM levels over papyrus swamp vegetation - a correction approach
}

\author{
G. Petersen ${ }^{1}$, I. Lebed ${ }^{2}$, and N. Fohrer ${ }^{3}$ \\ ${ }^{1}$ HYDROC Consult, Langballig, Germany \\ ${ }^{2}$ Artic and Antarctic Research Institute, St. Petersburg, Russia \\ ${ }^{3}$ Christian-Albrechts-University of Kiel, Ecology Centre, Department of Hydrology and Water Resources Management, \\ Kiel, Germany
}

Received: 20 January 2009 - Revised: 17 March 2009 - Accepted: 28 April 2009 - Published: 12 August 2009

\begin{abstract}
The SRTM DEM, a digital elevation model based on the Shuttle Radar Topography Mission of February 2000 is a source of elevation data with nearly worldwide coverage. It has proven its usefulness in various regions but problems persist for densely vegetated areas where, caused by the organic matter and water content of the vegetation, the radar signal is reflected at some level between the vegetation canopy and the ground level. This level varies with different types and densities of vegetation cover and has so far not been assessed for papyrus areas. The paper describes the approach and establishment of a correction factor for a pilot area in the Sudd swamps of southern Sudan based on comparison of SRTM reference levels and ground control points collected during field surveys between 2004 and 2006. Results show a correction factor between the sensed and the real surface of $4.66 \mathrm{~m}$ and a average penetration depth of the radar signal into the dense papyrus vegetation of $0.34 \mathrm{~m}$.
\end{abstract}

\section{Introduction}

The Nile swamps of southern Sudan, called the Sudd, one of the largest wetlands in Africa (Mohamed, 2005), is a densely vegetated inland delta system consisting of permanently inundated swamp and seasonal floodplains. The vegetation within the permanent swamp is luxurious year round. The area has been studied since the beginning of the last century and detailed area descriptions for the whole of the Sudd are available from Butcher (1938) and Hurst and Phillips (1938).

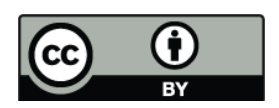

Correspondence to: G. Petersen (gpetersen@hydroc.de)
The JIT (1954) and Sutcliffe (1957) provided detailed descriptions of the southern part of the swamps, while Petersen (2008) assessed the central Sudd section north of the town of Bor, both authors providing detailed description of the morphology of the respective areas. For a large scale morphological assessment of the Sudd, considering its remoteness and difficulty of access, digital elevation models (DEM) based on remote sensing data are useful. The SRTM Shuttle Radar Topography Mission (NASA, 2009a) provided such information with good data quality for the less vegetated or burnt floodplains (Petersen et al., 2008). On the other hand, the densely vegetated permanent swamp area with its open water lagoons and up to six meter high papyrus fields as shown in the aerial overview in Fig. 1 is challenging the DEM accuracy. Within the papyrus fields, the dense vegetation with its organic matter and water content leads to an early reflection of the radar signal at some level between the vegetation canopy and the ground or water level, leading to errors of surface elevation data.

The objective of this paper is to describe and quantify the penetration depth of the radar signal into papyrus swamp vegetation of the Sudd, and to establish a correction factor to calculate true ground or water surface elevation in a pilot area between Bor and Shambe for which ground control points are available from field surveys (Petersen et al., 2008). The resulting correction factor will allow generating a corrected DEM, providing an improved base for morphological assessments and hydrological studies. A schematic sketch of the approach, showing the false surface that is generated by the early radar signal reflection (backscatter) in the papyrus vegetation is shown in Fig. 2. The established correction factor can be assumed to be potentially applicable for similar vegetation conditions worldwide. 


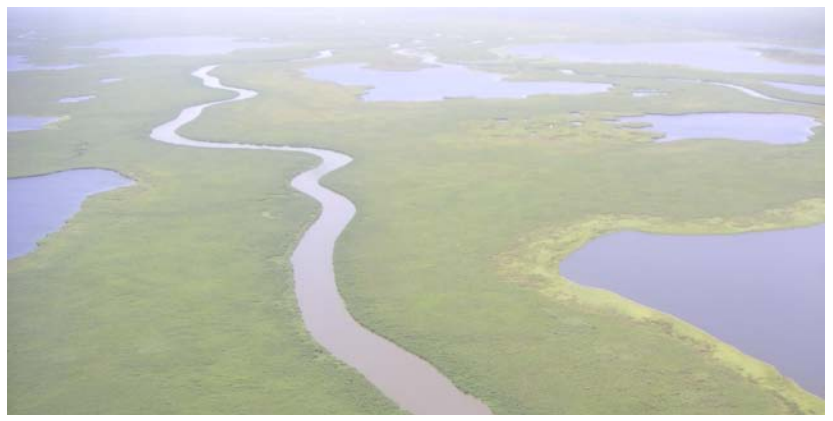

Fig. 1. Aerial photograph of the permanent swamp area with channels, lagoons and papyrus areas, taken during an aerial assessment in 2004 over the swamps between Bor and Shambe.

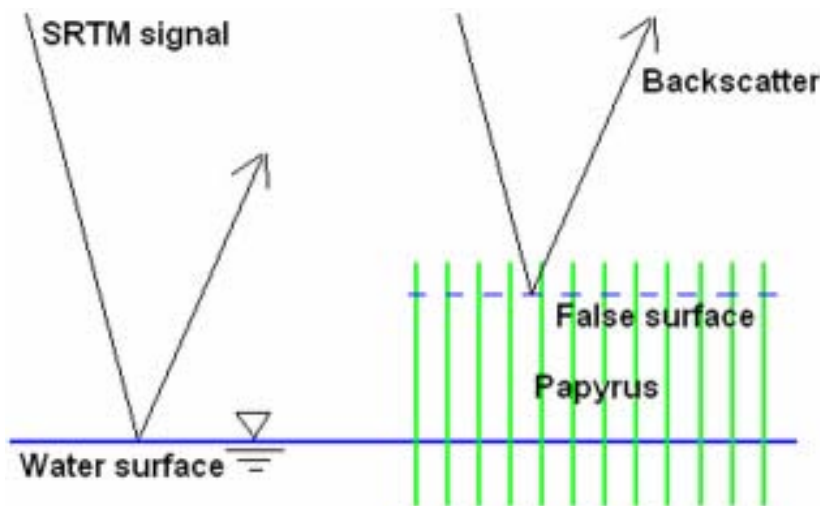

Fig. 2. Schematic sketch of comparison approach between lagoon and papyrus areas.

\section{Methods}

Version-2 improved SRTM DEM (NASA, 2009a) data as well as ground control points collected by DGPS (Differential Global Positioning System), optical level surveys and from historic topographical maps as e.g. from Euroconsult (1981) have been used to carry out the assessment described in this study. The SRTM data was downloaded from the NASA (2009a) website, and checked for consistency with ground control points available for the area of interest between Bor and Shambe (Petersen et al., 2008). An overview of the area is shown in Fig. 3. Within the ArcGIS 9 environment, the DEM was then overlaid with a dry season visual bandwidth Landsat image composite, scene P173R055, acquired on 11 July 2000 (NASA, 2009b) showing lagoons, main channels, papyrus areas and dry floodplains with the different elements being verified based on area observations that have been collected during site assessments between 2004 and 2006 (Petersen, 2008). The image was georeferenced with the underlying DEM layer. Reference points randomly distributed at 150 different locations in the area of interest were identified based on the lagoon, papyrus and land ground class areas. As shown in the close-up in Fig. 3, adja-

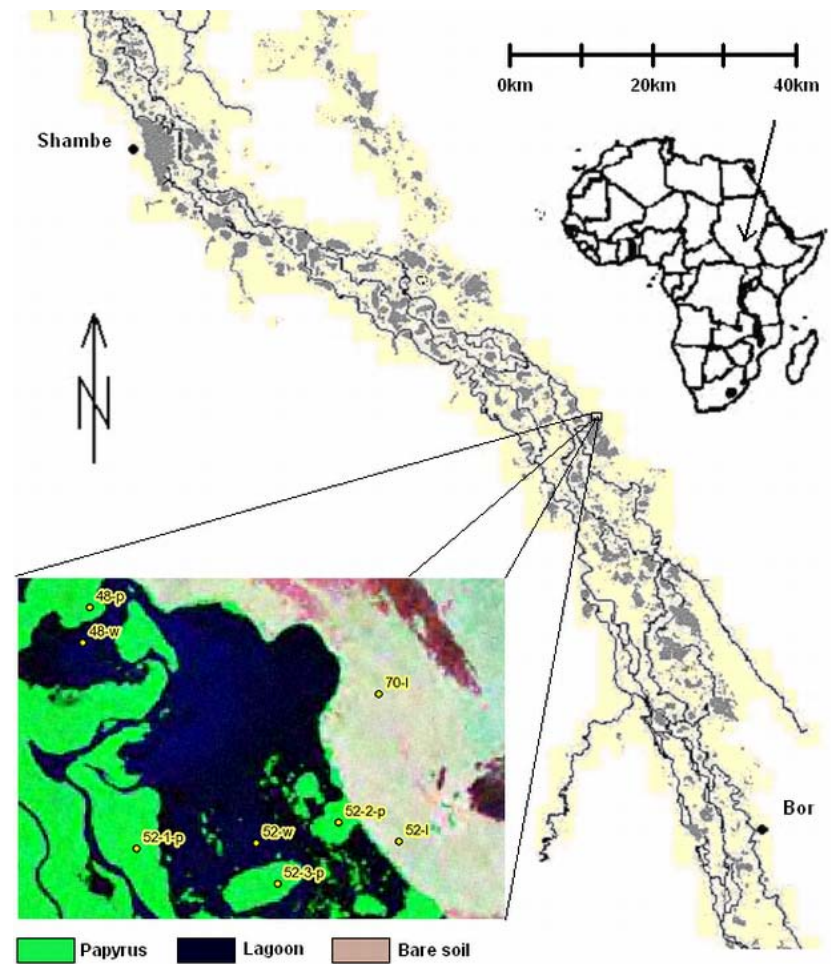

Fig. 3. Area overview map derived from Landsat image interpretation with zoomed in example area showing some local sample points out of the 150 points randomly distributed between Bor and Shambe.

cent matching sets of points were used to compare the level differences between lagoon-papyrus and lagoon-land ground class locations. Using this approach, care was taken to use DEM cells that were completely situated within the different ground class areas in order not to introduce errors due to interpolated ground class areas where cells covered both papyrus and lagoons.

The elevations for the selected locations were then exported and points located on the floodplains were checked for consistency comparing them to known ground control points and as well by conducting a consistency test comparing them to the adjacent lagoon areas, considering that the former should be slightly higher than the latter. To deduce the correction factor for the papyrus areas, the average difference between the adjacent lagoon and papyrus points was calculated, assuming that the water elevation in both the lagoon and within the adjacent papyrus field is similar. The results were then averaged, the correlation of the different groups of points analyzed and outliers removed, leading to an average correction factor for the papyrus area. This correction factor, deducted from the SRTM elevations in these areas, allows for the approximation of the real water surface elevation below the papyrus canopy. 


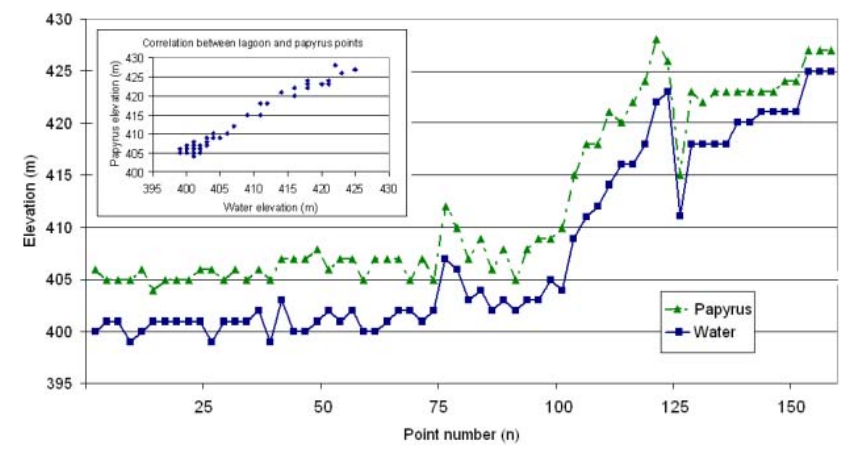

Fig. 4. Comparison of adjacent lagoon and papyrus elevation points as extracted from SRTM DEM. The points are sorted according to their ordering number. The inlay shows the correlation between the lagoon and papyrus elevation.

\section{Results}

Elevation data for 150 control points was exported from the SRTM version-2 DEM (NASA, 2009a), providing a reference elevation set for adjacent points in the lagoon, papyrus and land areas as shown in Fig. 3. The evaluated data shows an average difference of $4.66 \mathrm{~m}$ with a standard deviation of $1.45 \mathrm{~m}$ and a correlation coefficient of 0.987 between the papyrus and lagoon areas. This evaluation allows the assumption that the SRTM radar signal is reflected close to the papyrus vegetation canopy, in average $4.66 \mathrm{~m}$ above the real water surface, and that penetration depth into the papyrus vegetation is comparatively small. Figure 4 shows the distribution of the values for the 150 assessed points.

Migahid (1948) reported the average papyrus height as five meter, from which a penetration depth of the SRTM signal of $0.34 \mathrm{~m}$ can be deduced when deducting the $4.66 \mathrm{~m}$ radar reflection height. Comparing the evaluated dataset on a point pair basis, a correlation coefficient of $R=0.98$ was found, indicating consistent penetration depth conditions within the assessed area. This finding is confirmed by graphical interpretation of the differences (Fig. 4). The observed standard deviation of $1.45 \mathrm{~m}$ for the $4.66 \mathrm{~m}$ correction factor may be related to differences in vegetation height leading to changing correction factor values while the penetration depth maintains relatively consistent. Seasonal differences caused by changing vegetation status were judged as insignificant as field surveys showed that the papyrus roots are permanently inundated and the vegetation did not change over the year. An overview of the elevation difference distribution between water and papyrus levels is shown in Fig. 5.

The graph shows a relatively flat curve, with only $45 \%$ of the points showing $\mathrm{a}+/-0.5 \mathrm{~m}$ difference from the average $4.66 \mathrm{~m}$ elevation difference. This finding confirms the above assumed varying vegetation height, a finding also qualitatively confirmed based on field work observations where differences in height for different papyrus fields have been observed while their density was judged as relatively uniform.

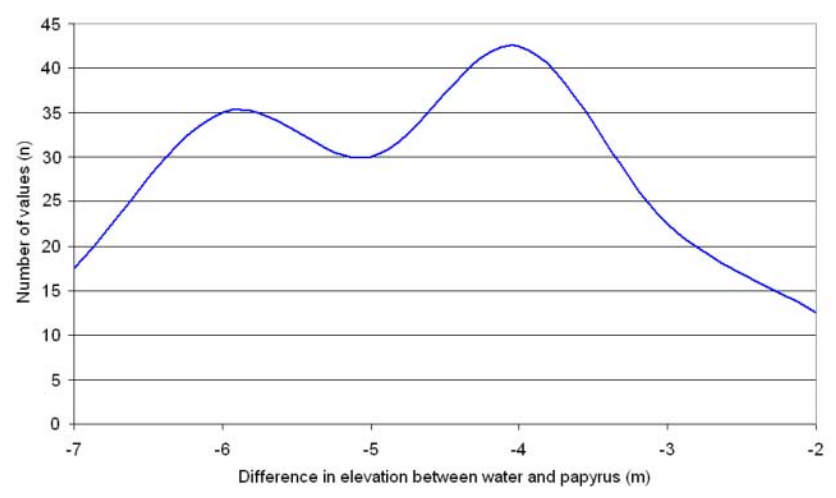

Fig. 5. Distribution of elevation differences between water and papyrus elevation.

\section{Discussion}

Comparing lagoon water surface elevations with adjacent papyrus field elevations in the SRTM data, an average difference of $4.66 \mathrm{~m}$ can be observed. In comparison to the height of the papyrus vegetation showing an average height of five meter and reaching up to six meter (Migahid, 1948) the results indicate that the SRTM radar signal is reflected close to the vegetation canopy. In the assessed case, the radar signal in average only penetrates $0.34 \mathrm{~m}$ into the dense papyrus field vegetation. Penetration depth may be greater in cases where the papyrus vegetation is less dense, the data available for the study does not allow for more detailed assessments. With no other study so far being conducted for swamp or wetland areas with papyrus vegetation, the results were compared with assessments of mainly woody areas as conducted by Kellndorfer et al. (2004) and Hofton et al. (2006) who assessed the effect of vegetation on SRTM accuracy. These studies show that for the assessed heterogeneous vegetated areas different magnitudes of errors occur and that the magnitude of the errors depends on the vegetation type and density by having an effect on the penetration depth and backscatter characteristics of the radar signal. Penetration depth in the assessed cases was shown as ranging from 3.3 to $26.3 \mathrm{~m}$ for more or less dense woody vegetation types. In comparison to the heterogeneous conditions assessed by the above authors, the papyrus fields of the Sudd region assessed in this study show a homogenous vegetation type with even biomass and water content distribution. These conditions result in a relatively even penetration depth and related radar backscatter error value for which variations can be related to total vegetation height variations.

\section{Conclusion and outlook}

Compared to the heterogeneous conditions described in the studies by Kellndorfer et al. (2004) and Hofton et al. (2006), the even radar backscatter behaviour and homogenous 
vegetation distribution and density in the Sudd yields a representative average correction factor of $4.66 \mathrm{~m}$, applicable for the papyrus fields in the permanent swamp areas. The homogenous distribution will allow for the application of the derived value as a general reduction factor to correct the SRTM elevation in the papyrus fields to a "real" water surface elevation in order to generate a correct surface elevation DEM. While in previous studies assumptions about the "real" surface elevation within the papyrus fields have been used, the derived correction factor of this study will allow for a better representation of levels within the papyrus fields and respective improved results for e.g. hydrodynamic assessments.

Edited by: B. Schmalz, K. Bieger, and N. Fohrer

Reviewed by: two anonymous referees

\section{References}

Butcher, A. D.: The Sadd Hydraulics, Government Press, Cairo, Egypt, 1938.

Euroconsult: Kongor Flood Protection Surveys, Draft Final Report, Arnhem, The Netherlands, 1981.

Hofton, M., Dubayah, R., Blair, J. B., and Rabine, D.: Validation of SRTM Elevations over Vegetated and Non-Vegetated Terrain Using Medium Footprint Lidar, Photogr. Eng. Remote Sens., 72(3), 279-285, 2006
Hurst, H. E. and Phillips, P.: The Nile Basin, Volume V, The Hydrology of the Lake Plateau and the Bahr el Jebel, Schindler Press, Cairo, Egypt, 1938.

JIT: The Equatorial Nile Project and its Effects on the AngloEgyptian Sudan, I-IV, Sudan Government, Khartoum, Sudan, 1954.

Kellndorfer, J., Walker, W., Pierce, L., Dobson, C., Fites, J. A., Hunsaker, C., Vona, J., and Clutter, M.: Vegetation height estimation from Shuttle Radar Topography Mission and National Elevation Datasets, Remote Sens. Environ., 93, 339-358. 2004.

Migahid, A. M.: Report on a Botanical Excursion to the Sudd Region, Fouad I University, Cairo, Egypt, 1948.

Mohamed, Y. A.: The Nile Hydroclimatology: Impact of the Sudd Wetland, Delft University of Technology, Delft, The Netherlands, 2005.

NASA: Shuttle Radar Topography Mission, http://www2.jpl.nasa. gov/srtm/, last access: 18 January 2009, 2009.

NASA: The Landsat Program, http://geo.arc.nasa.gov/sge/landsat/ landsat.html, last access: 18 January 2009b, 2009.

Petersen, G.: The Hydrology of the Sudd - Hydrological Investigation and Evaluation of Water Balances in the Sudd Swamps of Southern Sudan, PhD Thesis, University of Kiel, Germany, 2008.

Petersen, G., Sutcliffe, J. V., and Fohrer, N.: Morphological analysis of the Sudd region using land survey and remote sensing data, Earth Surf. Proc. Land., 33(11), 1709-1720, 2008.

Sutcliffe, J. V.: The Hydrology of the Sudd Region of the Upper Nile, PhD Thesis, Cambridge University, Cambridge, 1957. 